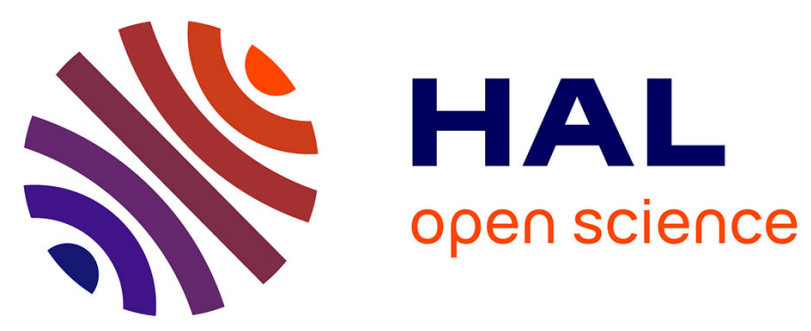

\title{
Numerical and Experimental Investigations on Deep Drawing of G1151 Carbon Fiber Woven Composites
}

\author{
A Gherissi, F Abbassi, Amine Ammar, A Zghal
}

\section{To cite this version:}

A Gherissi, F Abbassi, Amine Ammar, A Zghal. Numerical and Experimental Investigations on Deep Drawing of G1151 Carbon Fiber Woven Composites. Applied Composite Materials, 2016, 23 (3), pp.461-476. 10.1007/s10443-015-9468-x . hal-01361888

\section{HAL Id: hal-01361888 \\ https://hal.science/hal-01361888}

Submitted on 7 Sep 2016

HAL is a multi-disciplinary open access archive for the deposit and dissemination of scientific research documents, whether they are published or not. The documents may come from teaching and research institutions in France or abroad, or from public or private research centers.
L'archive ouverte pluridisciplinaire HAL, est destinée au dépôt et à la diffusion de documents scientifiques de niveau recherche, publiés ou non, émanant des établissements d'enseignement et de recherche français ou étrangers, des laboratoires publics ou privés. 


\title{
Numerical and Experimental Investigations on Deep Drawing of G1151 Carbon Fiber Woven Composites
}

\author{
A. Gherissi ${ }^{1}$ - F. Abbassi ${ }^{1,2}$ A. Ammar ${ }^{3}$ A. Zghal $^{1}$
}

\begin{abstract}
This study proposes to simulate the deep drawing on carbon woven composites in order to reduce the manufacturing cost and waste of composite material during the stamping process, The multi-scale anisotropic approach of woven composite was used to develop a finite element model for simulating the orientation of fibers accurately and predicting the deformation of composite during mechanical tests and forming process. The proposed experimental investigation for bias test and hemispherical deep drawing process is investigated in the G1151 Interlock. The mechanical properties of carbon fiber have great influence on the deformation of carbon fiber composites. In this study, shear angle-displacement curves and shear load-shear angle curves were obtained from a bias extension test. Deep drawing experiments and simulation were conducted, and the shear load-displacement curves under different forming depths and shear angle-displacement curves were obtained. The results showed that the compression and shear between fibers bundles were the main deformation mechanism of carbon fiber woven composite, as well as the maximum shear angle for the composites with G1151 woven fiber was $58^{\circ}$. In addition, during the drawing process, it has been found that the forming depth has a significant influence on the drawing force. It increases rapidly with the increasing of forming depth. In this approach the suitable forming depth deep drawing of the sheet carbon fiber woven composite was approximately $45 \mathrm{~mm}$.
\end{abstract}

Keywords Carbon fiber woven · Bias test $\cdot$ Shear angle $\cdot$ Anisotropic approach $\cdot$ Finite elements modelling $\cdot$ Forming

1 URMSSDT- ENSIT, 5 Avenue Taha Hussein, BP, 56, 1008 Bâb Manara, Tunisia

2 Mechanical Engineering Department, College of Engineering, Dhofar University, PO Box 2509, Postal Code 211 Salalah, Sultanate of Oman

3 ENSAM Arts et Métiers Paris-Tech d'Angers, 2 boulevard du Ronceray BP 93525, 49035 Angers, CEDEX 01, France 


\section{Introduction}

Being lightweight, facility of manufacturing processes and saving energy are the main objectives of aircraft and automobile industry. To improve the fuel efficiency, we need to reduce the weight of vehicles. Many experimental results show that approximately $40 \%$ of automobile fuel consummation is used to overcome the inertia of the cars in motion [1]. Traditional manufacturing technologies such as extrusion forming, resin transfer molding, compression molding are time-consuming and inefficient. However, the thermal stamp process is considered as an efficient manufacturing technology for carbon fiber woven composites (CFWC) [1]. The stamping operating parameters e.g. temperature, speed and blank holder force have a direct influence on wrinkles of the parts [1]. This problem has been resolved through the development of multi-scale approaches [2-6].

For instance, Boisse et al. [7, 8], Xiongqi Peng et al. [9] developed an approach based on in-plane shear rigidity and numerical solution. A hypo-elastic model has been used with representing the unit cell of the woven composite by four nodes. This approach was examined through simulations of a hemispherical forming process.

Ben Boubaker et al. $[10,11]$ used a pure discrete approach where the fabric were described initially by Fourier series development, the yarns were discretized into elastic straight bars. Stretching springs are connected by the frictionless hinges. The motion of each node was described by lateral and rotation displacements. The compressibility was expressed as a kinematic relationship, considering frictionless motions of the yarns.

The most common industrial application of woven composite is formed by injecting resin on the pre-formed reinforcement (RTM) or by using pre-impregnated composite thermoplastic matrices (CFRTP). The simulation results showed a significant reduction in fabric forming cost, see the investigation of S.P. Haanappel et al. [12], P. Harrison et al. [13] and S. Gatouillat et al. con [14]. However, the simulation became more difficult due to the increase of the fabric's complexity. Due to the special behavior of the interlock fabric G1151, several studies were developed to explain the different phenomena that appear during the forming process. Allaoui et al. [15, 16] show advanced application of the composite woven reinforcement G1151 used in aeronautics. The work presented by Launay J. et al. [17] demonstrate that the forming processes of G1151 the tensions become significant and play a role in the wrinkle formation by modifying the shear stiffness. In this study, the G1151 fabric is now addressed.

In several publications, it is shown that the bending stiffness mainly determines the shape of the wrinkles. The rigidity must be taken into account in the simulations in order to verify that wrinkles do not extend to the useful part of the preform [18]. Boisse et al. [18] show that the curvatures of the element are computed from the positions and displacements of the nodes of the neighboring elements. The size of the wrinkles increases with the bending stiffness [18]. To avoid supplementary degrees of freedom and consequently for numerical efficiency, Onate et al. [19] and Sabourin et al. [20] the bending stiffness is taken into account within an approach without rotational degree of freedom.

In this investigation, the punch and die were not heated, and the deformation region of the specimen was located in different sectors. Bias tests were conducted to examine the stamping and shear behavior of CFWC as well as the maximum shear angle of the woven carbon fiber. Deep drawing experiments were conducted to study the suitable forming holding method and deformation behavior. The FE simulation based on anisotropic multi-scale approach was also 
used to investigate fiber movement in the deformation process. The present model gives a novel alternative for the multi-scale simulation of woven fabric composites by using an anisotropic methodology approach for simulating woven composite's behavior.

\section{Woven Fiber Deformation Test Properties}

\subsection{Woven Fabric}

The specimen utilized in this study was a $2.5 \mathrm{D}$ woven interlock [G1151 from Hexcel ${ }^{\circledR}$ see Table 1]. The woven carbon fiber is composed of many interwoven yarns, as shown in Fig. 1.

The section dimensions of the yarn (bundle) are $1.5144 \mathrm{~mm} \times 0.166 \mathrm{~mm}$ and the gap between fiber yarns is $0.1 \mathrm{~mm}$. According to the experimental requirement, the specimen was cut to a rectangular shape with dimensions of $260 \mathrm{~mm} \times 80 \mathrm{~mm}$ while the effective dimensions are $160 \mathrm{~mm} \times 80 \mathrm{~mm}$, as shown in Fig. 2 .

\subsection{Shear Angle}

In the forming process of the composite, the deformation properties depend on the mechanical properties of the carbon fiber and of the weaving reinforcing yarns. When woven fiber is under external force, the relative sliding of fabric ply and rotation of tows at their crossovers will occur. The variation in the angle of warp and weft fibers after deformation is defined as 'shear angle: $\gamma$ '.

As presented in Fig. 3, assuming that the angle between two crossing yarn fibers before deformation is $\alpha=90^{\circ}$, the resulting deformation due to external load will change the angle to become less than $90^{\circ}(\theta)$. In this case, the shear angle $(\gamma)$ can be defined as:

$$
\gamma=90^{\circ}-2 \theta
$$

\subsection{Experimental set-up and Procedure}

The tensile machine (Zwick/Roell BT1-FR010 TEW.A 50) used in this study consists of a special chuck jaws claws framework, which is composed of two clamp jaws. The jaws are tied to the connecting joint, so that the position and the angle can be varied. The carbon fiber sheet is clamped by two clamp arms to avoid sliding and to ensure the surface of the sheet is smooth.

Table 1 The characteristics of the material G1151

\begin{tabular}{|c|c|c|c|c|c|c|c|c|c|c|}
\hline Material & Company & Designation & Fibres & Weave & $\begin{array}{l}\text { Warp } \\
\text { texture }\end{array}$ & $\begin{array}{l}\text { Weft } \\
\text { texture }\end{array}$ & $\begin{array}{l}\text { Warp } \\
\text { Reputation }\end{array}$ & $\begin{array}{l}\text { Weft } \\
\text { Reputation }\end{array}$ & Thickness & $\begin{array}{l}\text { Surface } \\
\text { density } \\
\text { of fabric }\end{array}$ \\
\hline G1151 & Hexcel & $\begin{array}{l}\text { G1151 } 1000 \\
\text { INJECTEX } \\
\text { E012FS }\end{array}$ & Carbon & $3 \mathrm{X}$ & $\begin{array}{l}7.5 \\
\text { yarns } / \mathrm{cm}\end{array}$ & $\begin{array}{l}7.4 \\
\text { yarns } / \mathrm{cm}\end{array}$ & $50 \%$ & $50 \%$ & $1.1 \mathrm{~mm}$ & $600 \mathrm{~g} / \mathrm{m}^{2}$ \\
\hline
\end{tabular}




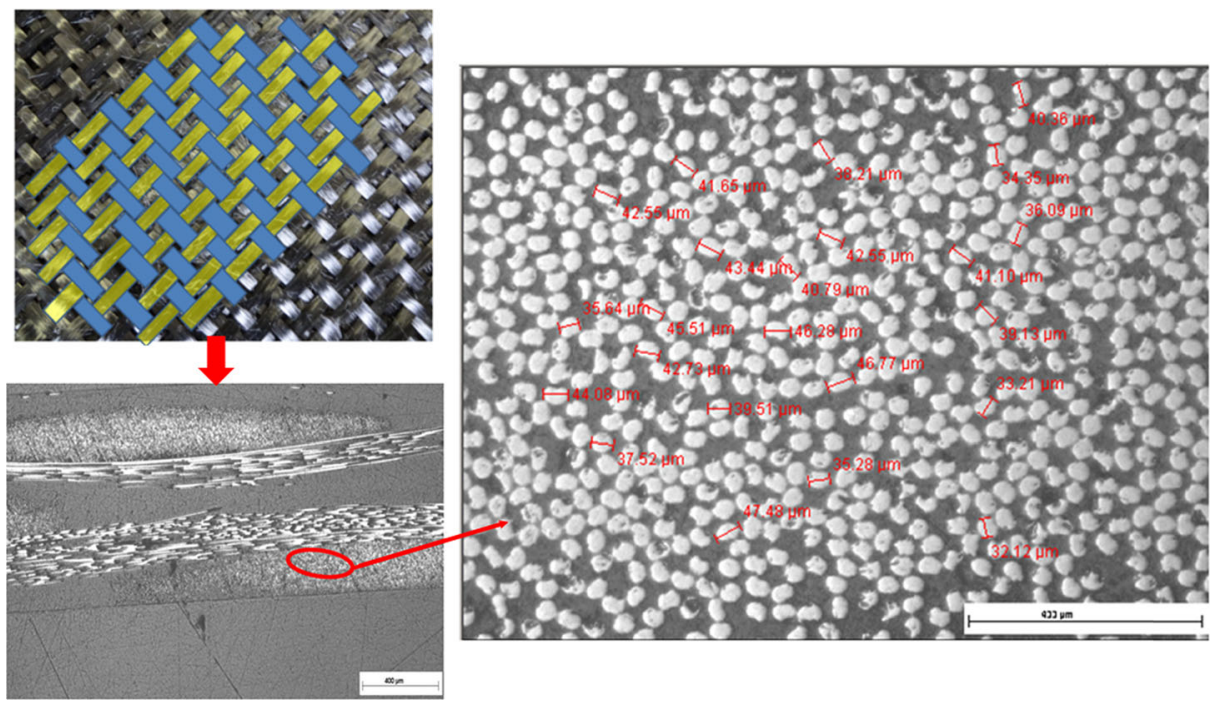

Fig. 1 Surface geometric characterization of the interlock G1151 fabric

The bottom of the clamp is connected to the base of the tensile machine while the top is connected to the slider of the testing machine. The woven carbon fiber specimen is cut into a rectangular shape with a fiber direction of $45^{\circ}$. The end of the specimen is clamped to the framework, and the load is applied at $45^{\circ}$ angle as shown in Fig. 4.

Prior to the bias extension test the specimen is mounted onto the fixture and then onto the tensile machine. The distance between two crossheads is adjusted until the specimen is fully stretched without any pre-tension. This position is considered as the reference point, e.g. zero displacement and no applied force.

Afterwards, the specimen is loaded at a tensile speed of $10 \mathrm{~mm} / \mathrm{min}$ and temperature of $20{ }^{\circ} \mathrm{C}$, and the variation in displacement and forces are automatically recorded until the occurrence of break off at some parts of the specimen (see Fig. 4).

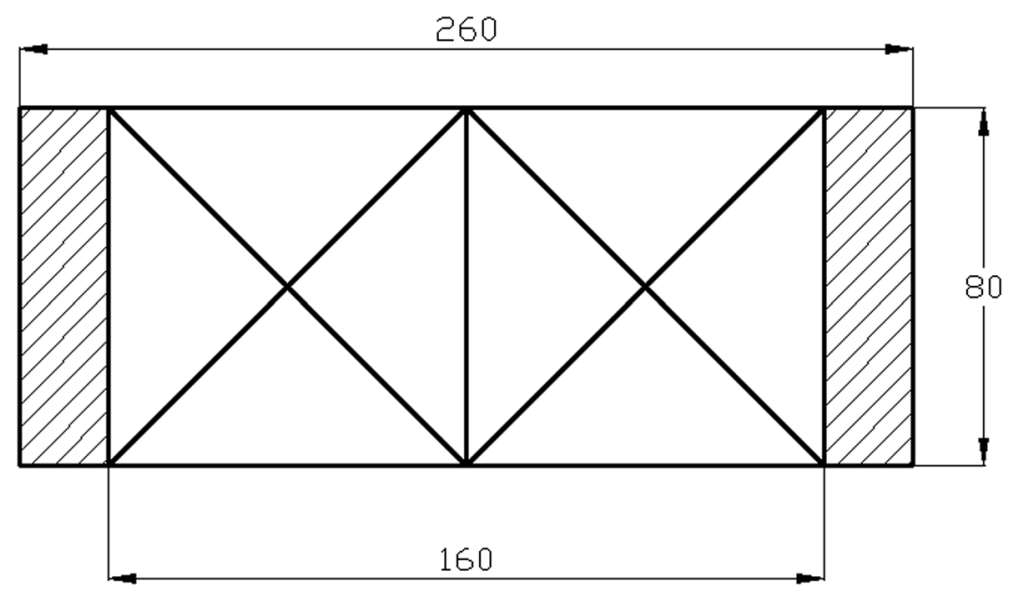

Fig. 2 Specimen's shape for bias extension test 


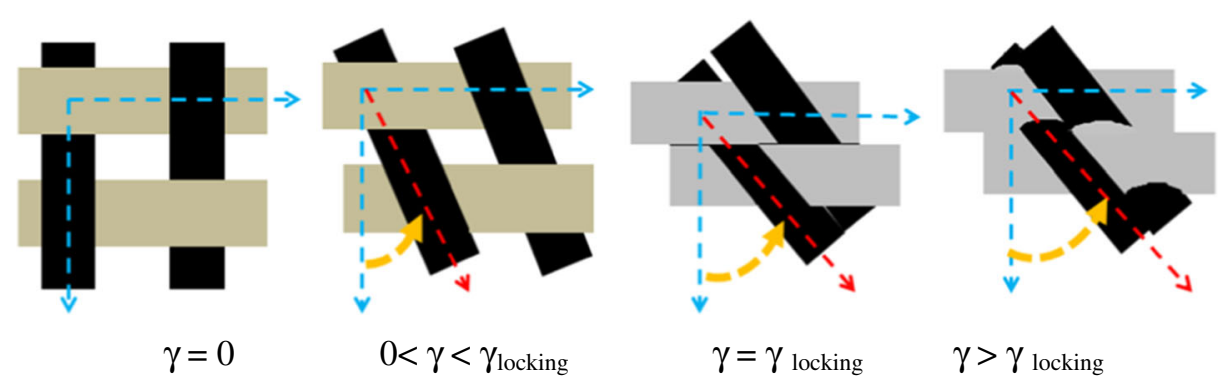

Fig. 3 Variation of the shear angle of RUC in accordance with displacement and the rotation of yarns $(\gamma$ initial $\left.=0^{\circ} / \alpha=90^{\circ}\right)$

After recovering the crosshead to zero point, the test was repeated five times to ensure an accurate result.

\subsection{Experimental Results}

To analyze the kinematics of the shear of the bias extension test, the following hypotheses are considered:

(i) The strain through portions of the specimen is homogeneous

(ii) The extension of the yarns at the elastic deformation is zero.

Three shear zones are considered to precisely study the kinematics of shear test which are (see Fig. 5):

- Zone A: The attachment areas of the specimen that are not sheared.

- Zone B: The central area which is highly sheared.

- Zone C: The partially sheared areas.

The approximation of the shear angle of zone "B" has already been developed by ([21, 22]), either through a) image analysis (digital image correlation method), or b) geometric study by calculating the angle using the following equations:

$$
\begin{gathered}
\cos \theta=\frac{\left(L_{0}+d\right)-L_{w}}{2\left(\left(L_{0}-L_{w}\right) \cos \theta_{0}\right.}=\cos \theta_{0} \frac{d}{2\left(\left(L_{0}-L_{w}\right) \cos \theta_{0}\right.} \\
\gamma=90^{\circ}-2 \theta=90^{\circ}-2 \cos ^{-1}\left(\frac{X_{1}}{\sqrt{2} X_{0}}\right)
\end{gathered}
$$

Or:

$$
\gamma^{\circ}=90^{\circ}-2 \frac{\operatorname{arcos}\left(X_{0}+d\right)}{\left(X_{0} * \sqrt{2}\right)}
$$

To observe the experimental process clearly, the three shear zones parts were bounded by white paint before the experiment. The deformation process of woven fabric G1151 has been showed in the selected photos in Fig. 6. The Fig. 7a show the shear load versus displacement 


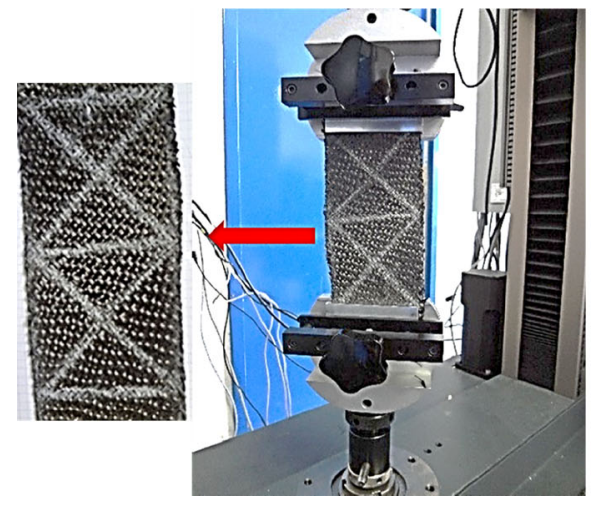

(a) G1151

simple. (b) The specimen before applicate the test.

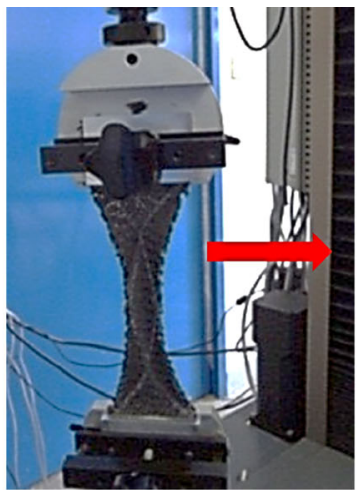

(c) Specimen during test

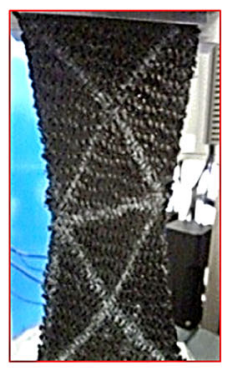

(d) The shear deformation in the specimen

Fig. 4 Bias-extension experimental test of woven fabric G1151

depicts the displacement of the moveable machine jaw as well as the variation of the shear load. The average shear angles of different displacements are calculated using Eqs. (2 and 3).

The measured shear load and the calculated shear angle are plotted in Fig. 7b, the normalized shear force $F_{\text {sh }}$ per unit length against the shear angle $\gamma$ can be approximated by the relation [16]:

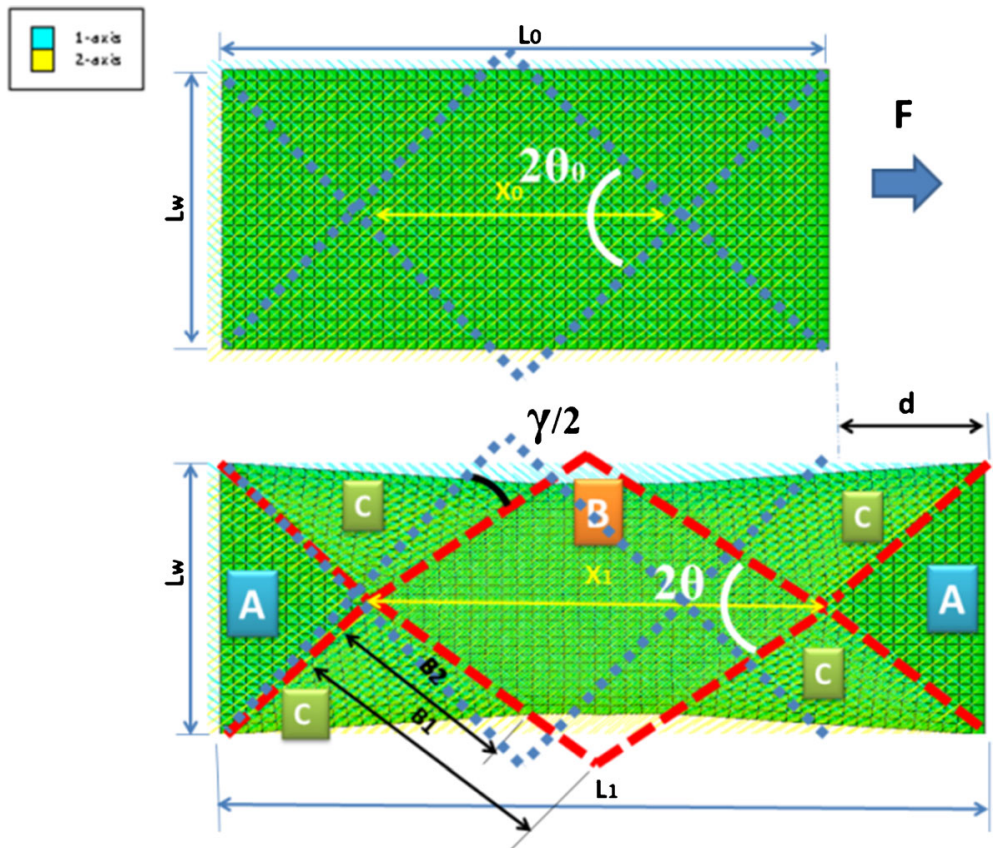

Fig. 5 Configuration of the bias-extension test: specimen at initial state and sheared state 


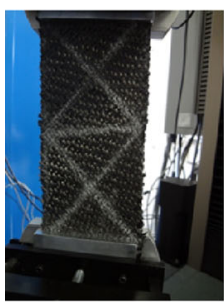

$\mathrm{d}=0 \mathrm{~mm}$

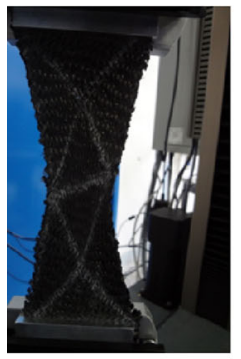

$\mathrm{d}=23.3 \mathrm{~mm}$

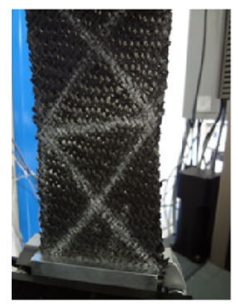

$d=5.3 \mathrm{~mm}$

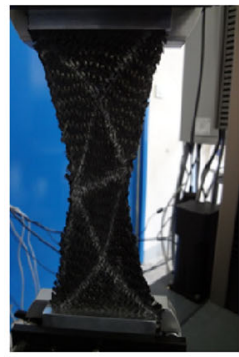

$\mathrm{d}=24.9 \mathrm{~mm}$

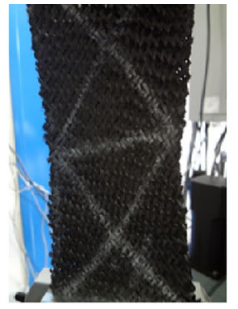

$d=9.9 \mathrm{~mm}$

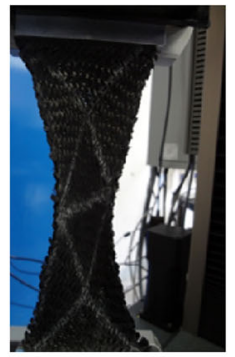

$\mathrm{d}=27.5 \mathrm{~mm}$

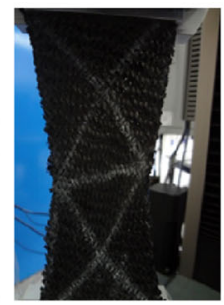

$\mathrm{d}=15.3 \mathrm{~mm}$

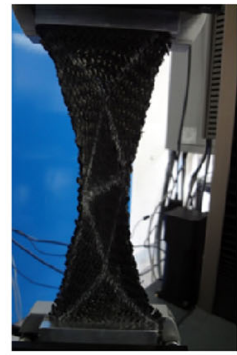

$\mathrm{d}=29.7 \mathrm{~mm}$

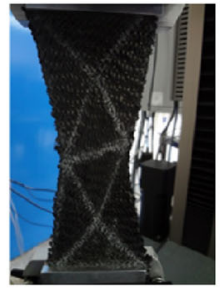

$\mathrm{d}=19.5 \mathrm{~mm}$

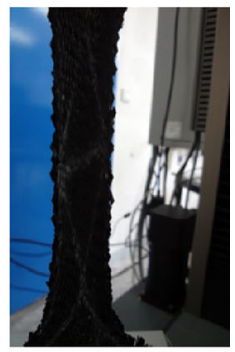

$\mathrm{d}=45.2 \mathrm{~mm}$

Fig. 6 Deformation process of woven in the Bias extension test ( $d$ is the displacement of the moveable machine jaw)

$$
F_{s h}(\gamma)=\frac{1}{\left(2 L_{0}-3 L_{w}\right) \cos \gamma}\left[\left(\frac{L_{0}}{L_{w}}-1\right) F\left(\cos \frac{\gamma}{2}-\sin \frac{\gamma}{2}\right)-L_{w} F_{s h}\left(\frac{\gamma}{2}\right) \cos \frac{\gamma}{2}\right]
$$

It can be seen that the non-linearity is the main feature of the relationship between the load and the shear angle. However, three different stages can be observed in this relation. In the first stage, the shear angle was smaller than $43^{\circ}$, the fiber bundles rotated and moved freely, and the external force is relatively small and increased linearly. In the second stage, the shear angle exceeded $43^{\circ}$, the shear rigidity of the fiber and the external load increased sharply, and the surface of the specimen becomes uneven and partial sticking occurred. The plausible reason behind such behavior is that, the increase in the shear angle causes the gradual increase in the overlapping area of the intersecting fiber bundles. Consequently, the intersecting fiber bundles will contract and push against each other so that no wrinkling occurs on the surface of the specimen. In third stage, the shear angle reaches the end limit when it was above $58^{\circ}$. At this point wrinkling can be seen on the surface of the specimen. Based on the qualitative information obtained from Fig. 7, it can be concluded that shear angle of $58^{\circ}$ is the forming limit of the woven carbon fiber in this experiment. When carbon fiber woven composites are processed using deep drawing forming technology, the forming parameters and die shape should be considered to ensure a shear angle less than $58^{\circ}$.

The deep drawing tests presented in this paper are carried out on a composite woven reinforcement denoted G1151 fabric. The shearing angle $43^{\circ}$ is considered as a secured forming angle. At $43^{\circ}$ the interlock yarns, weft and warp start contacting each other. This state could reflect the limit angle of the safe deep drawing process, if the limit is exceeded, the wrinkles might start appearing in some zones depending on the forming shape. By means of comparison with shear behavior of the G1151 material 


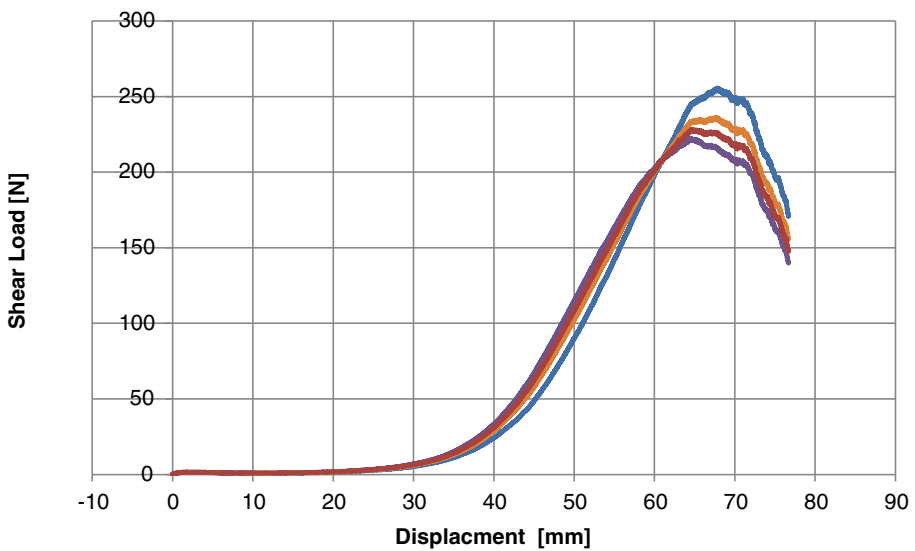

(a)

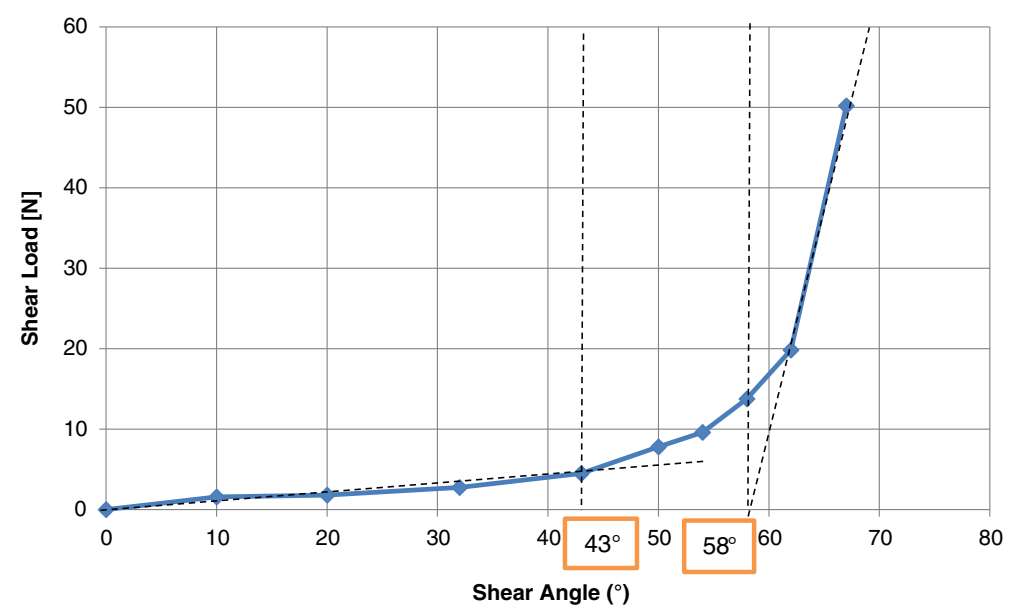

(b)

Fig. 7 a Shear load versus displacement, b Average Shear load versus shear angle during the deformation process of woven fabric $\mathrm{G}$

(Fig. 7), we conclude that the locking angle is not reached because it is less than the forming limit angle $58^{\circ}$. The results of experimental investigation done by Allaoui et al. [23], show that this material can be deformed up to $\left(\sim 50-60^{\circ}\right)$ as a shear angles in a critical zones (corners) without wrinkles.

\subsection{Simulation Results}

In this study, the numerical simulation is based on multistate modeling as described in the Fig. 8. The Micro-scale model was developed using MATLAB software by RVE with random distribution of micro fiber in the section. The results of this first stage of modeling are used as an input in the second phase of the multi scale study. The parameters of the material, taking in consideration the anisotropy of the fabric were 


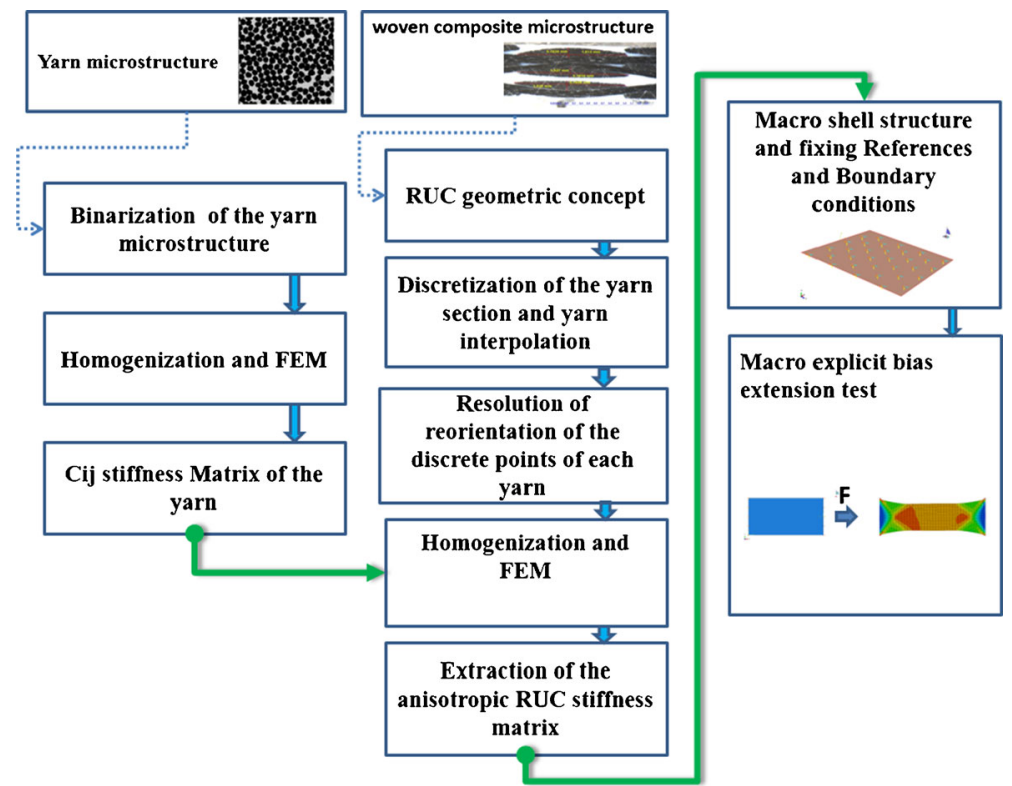

Fig. 8 Schematic diagram of multi-scale approach for bias extension test

deduced. To simulate the bias test and the forming operation in the macro scale model, a commercial software ABAQUS explicit was used. The FEM model was developed according to the parameters obtained during the meso-scale modeling. The stress-strain relation is described by the fully anisotropic elasticity constitutive equations with the independent elastic stiffness parameters available in abaqus [24]. The linear quadrilateral elements of type CPS4R was chosen to simulate the deformation of the woven fiber and the total number of elements is 1431 as shown in Fig. 9a.

The constraints of woven fiber and the movement of clamp were applied to the model and then a displacement of $60 \mathrm{~mm}$ was applied to the specimen., The variation in the shear angle was relatively small and it was concentrated at the center of the specimen as shown in Fig. 9(b).

Figure 10 shows the relation between the shear angle and the displacement for the calculated, simulated and experimental results. Eq. (4) has been used to calculate the shear angle while Fig. 5 is used to obtain the shear angle of the simulated data. Generally, all of the obtained results showed that a direct relationship between the shear angle and the displacement can be achieved, i. e. increasing the displacement causes the shear angle to increase. The relationship to some extent has a linear trend till the displacement reaches a value of approximately $25 \mathrm{~mm}$. In addition, the calculated and the simulated results are consistent with the experimental results.

\section{Deep Drawing Process}

Deep drawing is a classic forming process of stamping, which has been commonly used in industrial applications. In this study, a sheet of woven composite blank is 


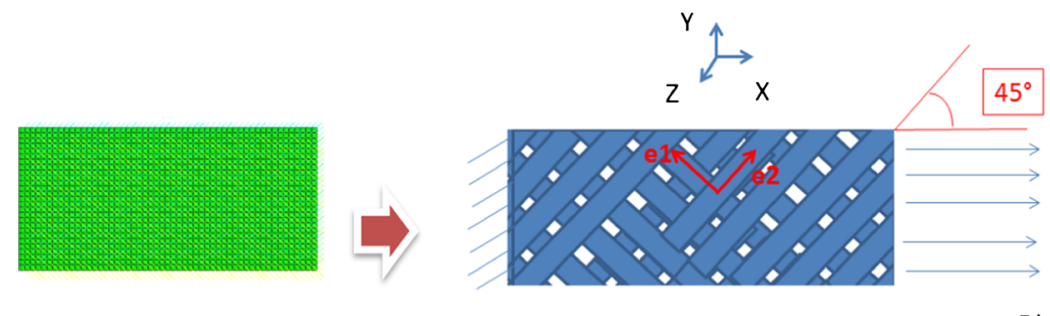

Displacement $U \mathrm{x}=0 ; \mathrm{Uy}=0 ; \mathrm{z}_{\mathrm{z}}=0$.

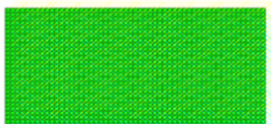

$\mathrm{d}=0 \mathrm{~mm}$
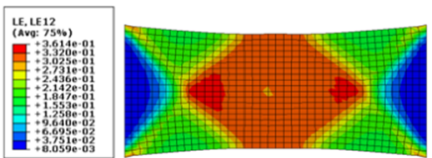

$\mathrm{d}=20 \mathrm{~mm}$
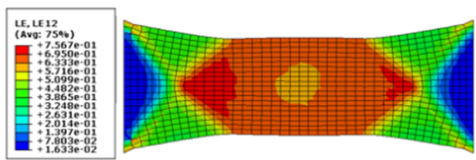

$\mathrm{d}=48 \mathrm{~mm}$
Displacement

$U x=x ; U y=0 ; U z=0$.

(a)

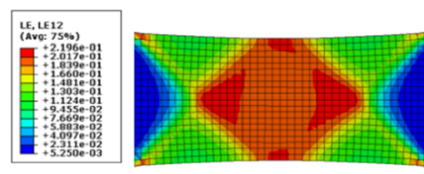

$\mathrm{d}=12 \mathrm{~mm}$

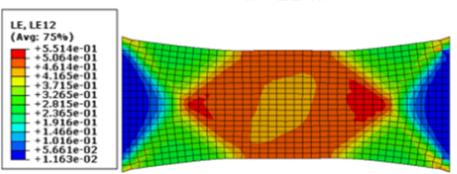

$\mathrm{d}=32 \mathrm{~mm}$

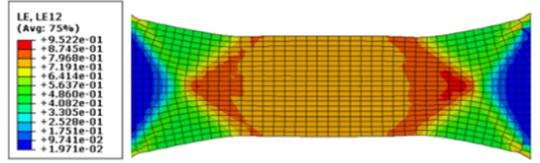

$\mathrm{d}=60 \mathrm{~mm}$

(b)

Fig. 9 a FEA model of the bias extension test and $\mathbf{b}$ Simulation results of the displacement distribution of woven fibers

radially drawn into a forming die by the mechanical action of a punch to manufacture hemispherical or rotating parts.

Fig. 10 Shear angle as a function of displacement of the experimental image analysis, simulation model and calculation method

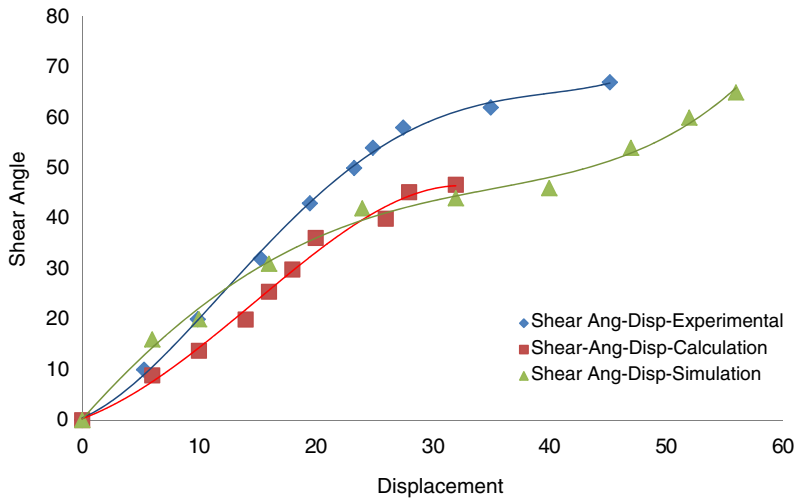




\subsection{Experimental set-up of the Deep Drawing Process}

Figure 11 shows the main steps of the deep drawing process. Firstly, the blank-holder is unloaded and the rectangular specimen is put on the surface of the die. Then the blank-holder is fixed with bolts to guide the woven sheet during forming. Before starting, a gap of $1 \mathrm{~mm}$ is kept between the blank-holder and the die. Secondly, a hydraulic pressure is applied on the punch.

The deep drawing die set consists of a die base, a punch, a blank-holder and a die. The hemispherical punch with a radius of $45 \mathrm{~mm}$ is connected to the upper base of the stress machine by clamp and bolts. The deep drawing die is connected to the lower base of the machine. The square specimen with a length side of $200 \mathrm{~mm}$ and thickness of $1.1 \mathrm{~mm}$ was used. The punch, blank-holder and die are made of high carbon steel.

\subsection{Experimental Results}

Deep drawing experiments of carbon fiber woven composites were conducted with stamping speed of $10 \mathrm{~mm} / \mathrm{min}$. Figure 12a shows the deformation of the carbon fiber woven composites. It can be seen that the woven fiber in the fiber length direction is pulled into the hemispherical cavity more remarkably than that at $45^{\circ}$ of the fiber direction, and the square specimen becomes nearly a fan with four blade wings.

Since the woven fabrics are composed of 3D weaving fibers, the deep drawing process causes re-distribution of fibers directions to obtain a new anisotropic shape. This is clearly shown in Fig. 12b where the variation in the shear angle is relatively small at the marked areas A, E and F while it concentrates at the marked areas B, C and $\mathrm{D}$.

During the deep drawing process, once the punch is removed, the fabric tends to relax a little. To keep it in position for the subsequent analysis of shear angles, a resin is put on surface to dry fast. Figure 13 illustrates several deep drawing parts of different drawing depth. It can be found that the surface of the specimen is smooth and the shape accuracy can be guaranteed by the punch and die.
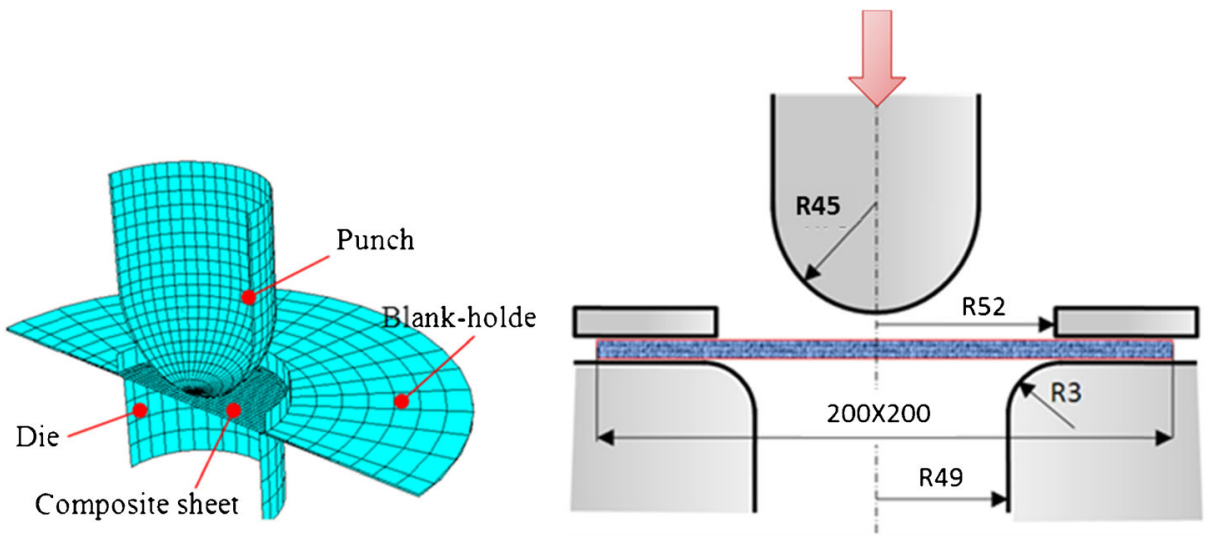

Fig. 11 Steps of the deep drawing process 


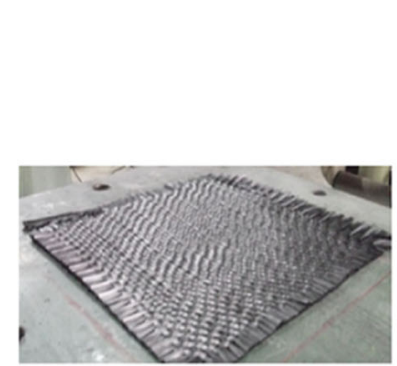

Specimen

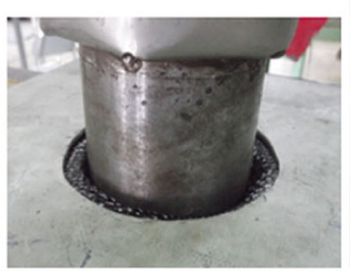

During deformation

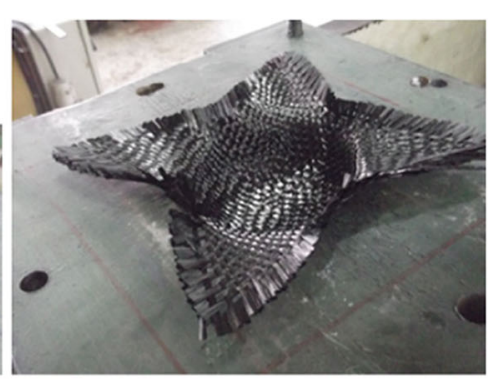

After deformation

(a)

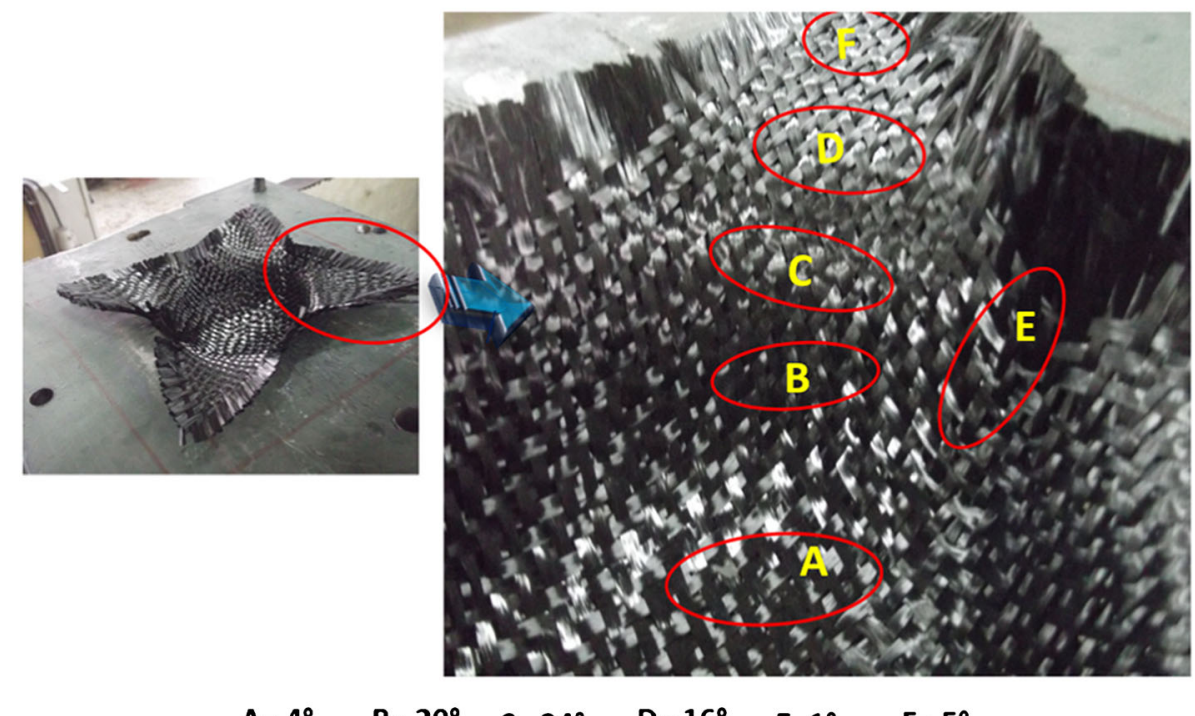

$A=4^{\circ} \quad B=20^{\circ} \quad C=24^{\circ} \quad D=16^{\circ} \quad E=1^{\circ} \quad F=5^{\circ}$

(b)

Fig. 12 a Deformation process steps and $\mathbf{b}$ Experimental shear angle distribution of deformed woven fibers

\subsection{Deep Drawings Simulation Results}

Deep drawing process was simulated using ABAQUS software under anisotropic multi-scale method. Due to the symmetry of the specimen only quarter of the shape was modeled and symmetrical constraints were applied as shown in Fig. 14. The linear quadrilateral element of type CPS4R was chosen to simulate the characteristic of the woven fiber with a total number of 1352 elements. The friction coefficient used in the simulation is considered as 0.3 . The punch and die were considered as a rigid body. The model was considered to move freely so only the deformation of woven was simulated.

The simulation results, as shown in Fig. 14, showed that the variation in the element angle was relatively large near the center of the specimen at $45^{\circ}$ of element direction, while minor variation occurred at the truss element direction. In addition, the simulation results showed that the shear angle was varied with the drawing depth, i.e. the shear angle increases from the top 


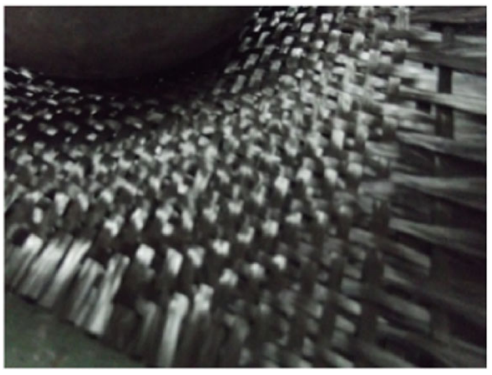

$$
\mathrm{d}=15 \mathrm{~mm} \quad \gamma=5^{\circ}
$$

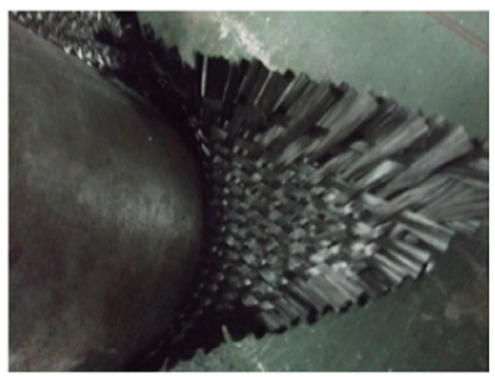

$\mathrm{d}=35 \mathrm{~mm} \quad \gamma=22^{\circ}$

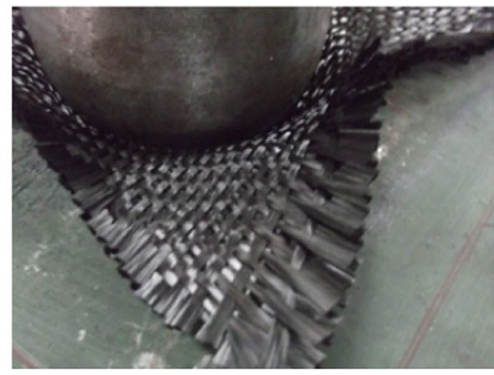

$\mathrm{d}=25 \mathrm{~mm} \quad \gamma=20^{\circ}$

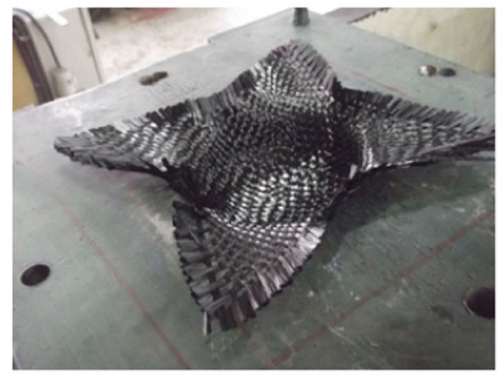

$\mathrm{d}=45 \mathrm{~mm} \quad \gamma=30^{\circ}$

Fig. 13 Deformed parts of different drawing depth

towards the center of the specimen as shown in Fig. 15. The increase in shear angle was more noticeable towards the center of the specimen.

Fig. 14 Deep drawing simulation model

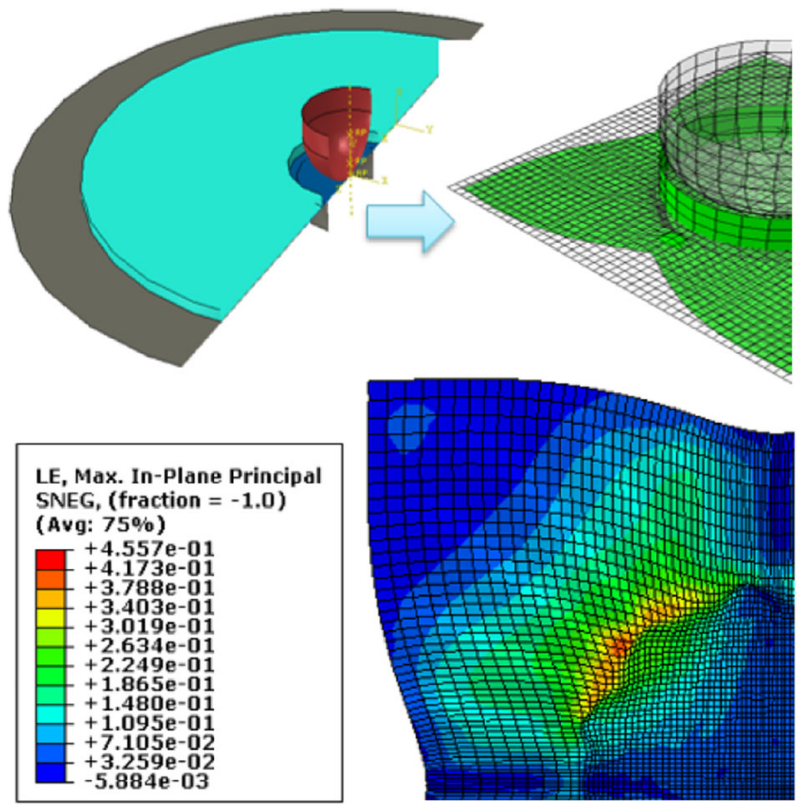


Fig. 15 Wrinkling direction at $45^{\circ}$

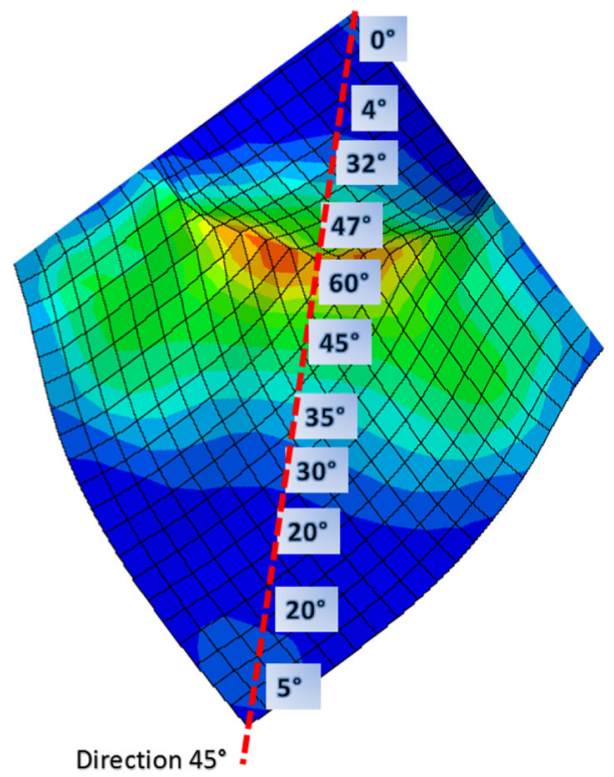

Figure 16 shows a comparison between the experimental and the simulation results of the shear angle. Noticeably, the shear angle increases exponentially with increase of the drawing depth. In addition, the trend of simulation results was generally consistent with the experimental results. However, the values of the shear angle obtained by the simulation were relatively lesser than that of the experimental results. It can be speculated that shear angle obtained in the simulation reflects the compression and shear between fibers bundles while in

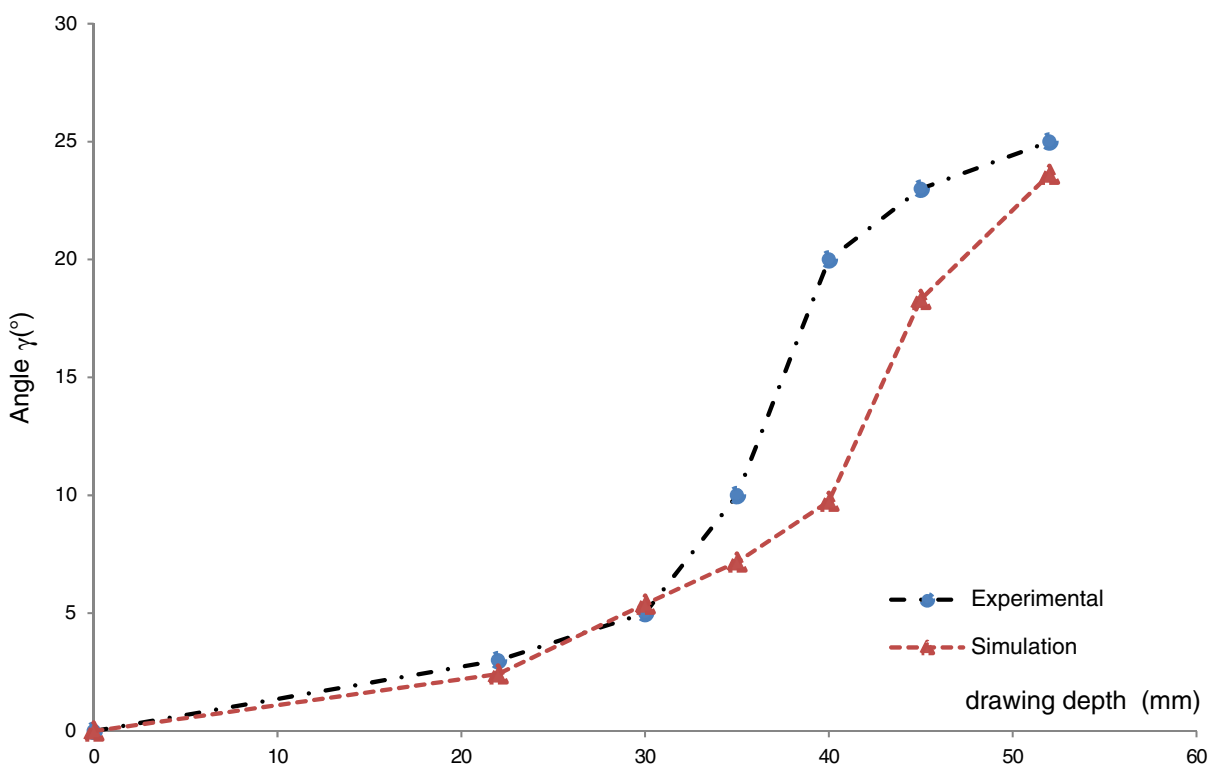

Fig. 16 Shear angle as a function of drawing depth for both the experimental and simulation results 
the experiments, the variation in fraction will interact with the fiber bundles, which induce forces to prevent the shear deformation process.

\section{Conclusion}

The shear properties of carbon fiber woven composites were investigated by bias extension tests and deep drawing experiments, and the conclusions are as follows:

The shear between fiber bundles and the compression are the main deformation mechanism of woven fiber. When the displacement is small, intersecting fiber bundles rotate slowly around the connection area, and adjacent fiber bundles move toward each other and friction between the fiber bundles is the main reason for the increase load. As the displacement increases, the internal force between fibers increases and adjacent bundles push against each other. During this process intersecting fiber bundles twist to prevent themselves from rotating around the crossovers, which results fast increase of shear load and appearance of dents on the specimen surface.

The shear load-shear angle curves obtained from bias extension test, gives that when shear angle is smaller than $45^{\circ}$, the shear load increases progressively with the increasing shear angle. When shear angle exceeds $45^{\circ}$, shear load increases fast, the curves become steep and wrinkling occurs on the surface of the specimen. Therefore $45^{\circ}$ is the maximum shear angle for carbon fiber woven G1151 in this study.

The deep drawing experiments showed that the drawing force increases significantly with increase of the drawing depth. The suitable drawing depth was approximately $45 \mathrm{~mm}$ with a shear angle of $30^{\circ}$. At these conditions wrinkling will occur on the surface of the specimen due to the occurrence of compression and shearing between fiber bundles which in turn causes a local project or dent to occur on the surface of the specimen during the deformation process.

The experimental results of deep drawing are consistent with simulation results. In the deep drawing process, the specimen changes from a square to a fan with four blade wings. This result was observed in the previous work of Q. Zhang et al. [1], E. De Luycker et al. [25] and A. Cherouat et al. [26]. It is because the fibers in the warp and weft direction are pulled into the cavity easily, and the surface is smooth. Whereas in zones at $45^{\circ}$ angle of fiber direction, the fibers bundles push and shear against each other, and rotation of yarns at the crossovers will occur in the bending parts of the die.

\section{References}

1. Zhang Q., Cai J., Gao Q.: Simulation and experimental study on thermal deep drawing of carbon fiber woven composites. J. Mater. Process. Technol. 214, 802-810 (2014)

2. Boisse Ph. Hamila N., Badel P., Vidal-Sallé E., Simulations éléments-finis de la déformation de textiles aux échelles macro et mésoscopique, Mécanique \& Industries 10, (2009)15-19.

3. Nguyen Q.T., Vidal-Sallé E., Ph B., Park C.H., Saouab A., Bréard J.: Hivet. G. Mesoscopic scale analyses of textile composite reinforcement compaction. Compos. Part B. 44(1), 231-241 (2013)

4. Sagar T.V., Potluri P., Hearle J.W.S.: Textile composites group: mesoscale modelling of interlaced fibre assemblies using energy method. Comput. Mater. Sci. 28, 49-62 (2003)

5. Assidi M., Ben B.B.: Ganghoffer J.F.. equivalent properties of monolayer fabric from mesoscopic modelling strategies. Int. J. Solids Struct. 48, 2920-2930 (2011)

6. Ten Thije R.H.W., Akkerman R., Huetink J.: Large deformation simulation of anisotropic material using an updated lagrangian finite element method. Comput. Methods Appl. Mech. Eng. 196, 3141-3150 (2007) 
7. Boisse P., Zouari B., Gassert A.: A mesoscopic approach for the simulation of woven fibre forming. Compos. Sci. Technol. 65, 429-436 (2005)

8. Boisse P., Zouari B., Daniel J.L.: Importance of in-plane shear rigidity in finite element analyses of woven fabric composite preforming. Composites Part A. 37-12, 2201-2212 (2006)

9. Peng X., Guo Z., Du T., Yu W.R.: A simple anisotropic hyperelastic constitutive model for textile fabrics with application to forming simulation. Compos. Part B. 52, 275-281 (2013)

10. Ben B.B., Haussy B., Ganghoffer J.F.: Discrete models of woven structures. Macroscopic Approach. Composites Part B. 38, 498-505 (2007)

11. Ben B.B., Haussy B.: Mesoscopic fabric models using a discrete mass-spring approach: yarn-yarn interactions analysis. J. Mater. Sci. 40, 5925-5932 (2005)

12. Haanappel S.P., Ten Thije R.H.W., Sachs U., Rietman B., Akkerman R.: Formability analyses of unidirectional and textile reinforced thermoplastics. Compos. Part A. 56, 80-92 (2014)

13. Harrison P., Gomes R., Curado-Correia N.: Press forming a 0/90 cross-ply advanced thermoplastic composite using the double-dome benchmark geometry. Compos. Part A. 54, 56-69 (2013)

14. Gatouillat S., Bareggi A., Vidal-Sallé E., Boisse P.: Meso modelling for composite preform shaping simulation of the loss of cohesion of the woven fibre network. Compos. Part A. 54, 135-144 (2013)

15. Allaoui S., Launay J., Soulat D., Chatel S., Experimental tool of woven reinforcement forming. Int. J. Mater. Form., April 2008 Volume 1, Issue 1, pp 815-818.

16. Allaoui S., Hivet G., Wendling A., Soulat D., Chatel S. (7-10 June, 2010). Experimental approach for optimizing dry fabric formability. the 14th European Conference on Composite Materials (ECCM 14), Budapest, Hungary, ID347- ECCM14.

17. Launay J., Hivet G., Duong A.V., Boisse P.: Experimental analysis of the influence of tensions on in plane shear behaviour of woven composite reinforcements. Compos. Sci. Technol. 68(2), 506-515 (2008)

18. Boisse P., Hamila N., Vidal-Salle E., Dumont F.: Simulation of wrinkling during textile composite reinforcement forming. Influence of tensile, in-plane shear and bending stiffnesses-. Compos. Sci. Technol. 71(5), 683 (2011)

19. Onate E., Zarate F.: Rotation-free triangular plate and shell elements Int. J. for Numerical Method in Engineering. 47, 557-603 (2000)

20. Sabourin F., Brunet M.: Detailed formulation of the rotation-free triangular element "S3" for general purpose shell analysis. Eng. Comput. 23(5), 469-502 (2006)

21. CAO J., Akkerman R., Boisse P., Chen J., Cheng H.S., de Graaf E.F., Gorczyca J.L., Harrison P., Hivet G., Launay J., Lee W., Liud L., Lomov S.V., Long A., de Luycker E., Morestin F., Padvoiskis J., Peng X.Q., Sherwood J.: Stoilova Tz., Tao X.M., verpoest I., Willems a., wiggers J., Yu T.X., Zhu B.: characterization of mechanical behavior of woven fabrics: experimental methods and benchmark results. Compos. A: Appl. Sci. Manuf. 39, 1037-1053 (2008)

22. Gatouillat S. Approche mésoscopique pour la mise en forme des renforts tissés de composites, $\mathrm{PhD}$ (2010) l'Institut National des Sciences Appliquées de Lyon.

23. Allaoui S., Hivet G., Soulat D., Wendling A., Ouagne P., Chatel S., Experimental preforming of highly double curved shapes with a case corner using an interlock reinforcement, Int. J. Mater. Form. 7 (2), 155-165

24. Abaqus Version 6.11, 2011. Analysis User's Manual. Dassault Systemes Simulia Corp., Providence, RI.

25. De Luycker E., Morestin F., Boisse P., Marsal D.: Numerical analysis of 3D interlock composite preforming. Int. J. Mater. Form. 1, 843-846 (2012)

26. Cherouat A., Louis B.J.: Mechanical and numerical modelling of composite manufacturing processes deepdrawing and laying-up of thin pre-impregnated woven fabrics. J. Mater. Process. Technol. 118, 460-471 (2001) 